Faculdade de Ciências Econômicas UFRGS
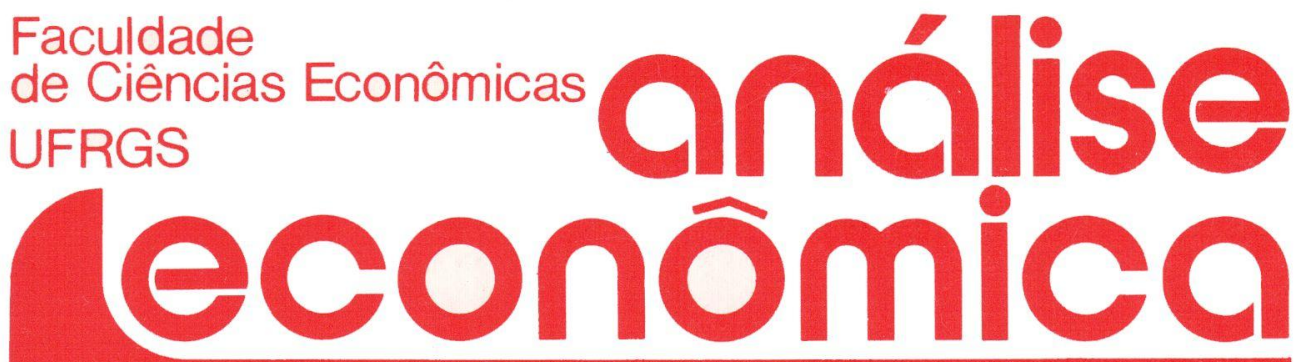

nesta edição:

- PRODUÇÃO DE ÁLCOOL E EMPREGO Otto G. Konzen e Juvir L. Mattuella

- NECESSIDADE DE PENSAR E CONSTRUIR O PÓS-CRISE Marcus Vinicius Pratini de Moraes

- CONTAS EXTERNAS

Fernando Ferrari Filho

- FETICHISMO

Leda Maria Paulani

- CRISE DO CAPITALISMO MUNDIAL Beki Morón de Macadar

- EXPANSÃO CAFEEIRA NO ESPÍRITO SANTO José L. Celin
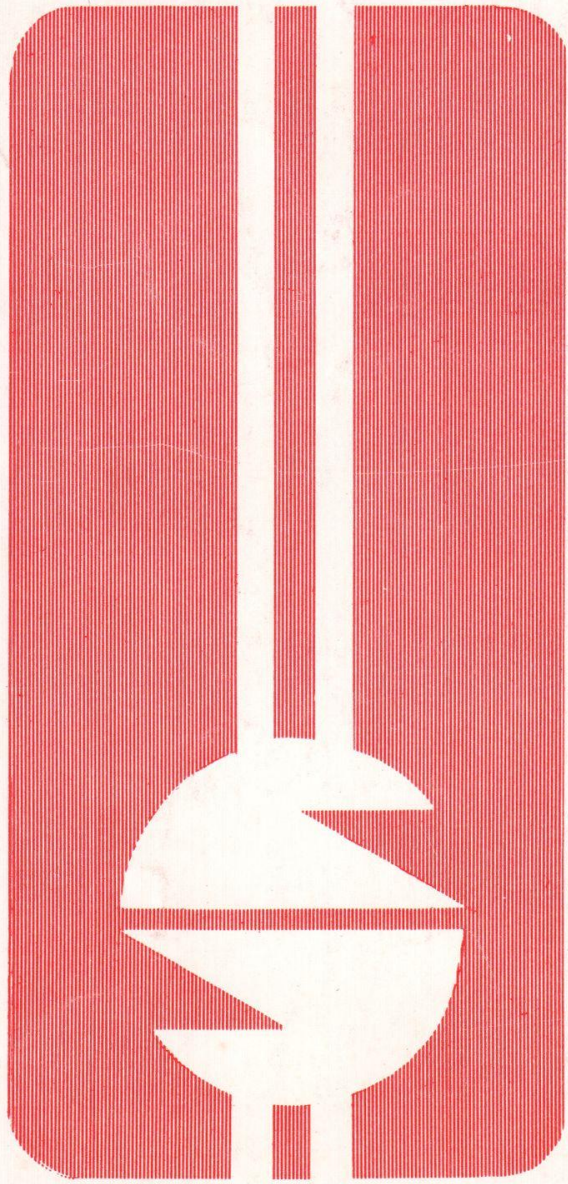
DIRETOR DA FACULDADE DE CIÉNCIAS ECONOMMICAS:

Prof. Antonio Carlos Santos Rosa/Prof. Edgar Irio Simm

VICE-DIRETOR:Prof. Nelson Rokembach/Prof. Walter Meucci Nique

CHEFE DO DEPARTAMENTO DE CIẼNCIAS ECONÔMICAS:

Prof. Renato Batista Masina

CONSElHo EdITORIAL: Prof. Pedro Cezar Dutra Fonseca (Presidente)

Prof. Achyles Barcelos da Costa

Prof. Carlos Augusto Crusius

Prof. Claudio Francisco Accurso

Prof. Edgar Augusto Lanzer

Prof. Ernani Hickmann

Prof. Nali de Jesus de Souza

Prof. Nuno Renan Lu de Figueiredo Pinto

Profa Otilia Beatriz Kroeff Carrion

Prof. Roberto Camps Moraes

Profạ Yeda Rorato Crusius

FUNDADOR: Prof. Antonio Carlos Santos Rosa

ANALISE ECONÔMICA publica dois números anuais, nos meses de março e novembro. O preço da așsinatura para 1985 é $\mathrm{Cr} \$ 6.000,00$, a ser pago através de cheque nominal para "Faculdade de Ciências Econômicas - UFRGS". Aceita-se permuta com revistas congêneres. Aceitam-se, também, livros para elaboração de resenhas ou recensões.

Toda a correspondência, material para publicação, assinaturas e permutas devem ser dirigidas a:

Prof. PEDRO CEZAR DUTRA FONSECA

Revista Análise Econômica

Avenida João Pessoa, $52-3 \%$ andar

90.000 - Porto Alegre (RS) - Brasil 


\title{
ECONOMIA BRASILEIRA: a necessidade de pensar e construir o pós-crise
}

\author{
MARCUS VINICIUS PRATINI DE MORAES*
}

A economia mundial encontra-se, neste momento, em mais uma de suas crises periódicas. Um dos ensinamentos que podemos extrair da história é que o desenvolvimento do capitalismo se processa em fases cíclicas, entendendo-se como ciclo econômico a repetição de movimentos que incluem as seguintes fases: crise, depressão, recuperação, crescimento e novamente crise, depressão, etc. A primeira Grande Depressão (1873-96) ocorreu na primeira fase do capitalismo industrial e foi uma seqüência de várias crises de superacumulação com base nas velhas tecnologias do carvão e da máquina de vapor, enquanto as novas tecnologias baseadas na eletricidade, no motor de combustão e em certos processos químicos - metálicos e orgânicos - não estavam suficientemente desenvolvidas para permitir toda uma vaga de grandes inversões que mudaram toda a base técnica do sistema produtivo. Quando estas ocorreram deu-se a superação da crise e a economia capitalista mundial entrou em outra fase de ascensão em que novas relações econômicas, sociais e políticas se impuseram.

A segunda Grande Depressão foi uma nova seqüência de crises cíclicas que culminaram na chamada crise econômica mundial dos anos de 1929 a 33. Diferentemente da anterior, a nova depressão caracterizou-se não só pela baixa taxa de lucro mas também por uma queda violenta no volume do comércio mundial, a destrui-

* Economista e Deputado Federal (RS).

ANÁLISE ECONO̊MICA

ANO 2

No 4

NOV./1984

p. 27.32 
ção do sistema monetário mundial baseado na libra esterlina e um aumento enorme do desemprego. Foi esta uma crise mais grave do que a anterior. Em sua superação combinou-se o resultado do advento de novas tecnologias como a eletrônica e a dos sintéticos e o uso generalizado do motor de combustão, que possibilitaram tanto o aumento da produtividade do trabalho via inovações dos processos produtivos como o aumento do emprego pela criação de uma gama de novos produtos e com a introdução de todo um instrumental de política econômica baseado nas concepções de John Maynard Keynes. Estas afirmavam que com o aumento do emprego e uma política de pleno emprego pela criação de uma demanda adicional pelo Estado seria possível, sem provocar tendências inflacionárias, expandir a renda dados alguns pressupostos realmente existentes nas economias capitalistas avançadas dos anos trinta.

A terceira Grande Depressão, que pode ser localizada a partir dos primeiros anos setenta, após um longo período de prosperidade, deu-se pela exacerbação dos fatores mesmos que ajudaram a alimentar a prosperidade: os déficits permanentes no balanço de pagamentos dos Estados Unidos - que destruíram a confiança no dólar e no funcionamento estável do sistema monetário internacional, gerando processos inflacionários por toda a parte; o uso ilimitado e irracional de matérias-primas, em especial o petróleo; o pleno emprego e a proteção do mercado de trabalho, provocando aumentos salariais acima da produtividade; o crescimento desmesurado das despesas estatais - em subsídios agrícolas, obras de infra-estrutura, benefícios sociais, levando ao déficit público e ao endividamento crescente do Estado. Todo esse quadro levou ao esgotamento do padrão tecnológico e do intervencionismo estatal que haviam permitido a superação da segunda Depressão. A saída da crise atual dependerá das alternativas que certamente serão encontradas nos dois campos que referimos. Essas alternativas não estão ainda muito claras, menos ainda no campo do papel do Estado do que no da inovação tecnológica, onde as surpreendentes revoluções da informática e da microeletrônica, da nova metalurgia e da engenharia genética abrem inúmeras perspectivas. No campo da ingerência do Estado, contudo, as perspectivas estão menos definidas: o que se vislumbra atualmente, a alternativa entre a postura neoconservadora de retorno ao Estado clássico do primeiro capitalismo e a postura imobilista dos keynesianos de manutenção do status $q u o$, não nos parece ser o melhor rumo para o futuro. Um terceiro caminho deve ser viabilizado que signifique a superação do déficit fiscal sem a perda de regulamentação estatal e do estado de bem-estar. 
Na esfera produtiva as transformações mencionadas serão, entre outras, caracter ísticas do desenvolvimento industrial nas próximas décadas. Com as grandes inovações tecnológicas, os setores de ponta deverão se localizar nos países centrais do sistema mun. dial. Entretanto, alguns poucos países da periferia, dentre estes o Brasil, poderão - em função de fatores como a base de recursos naturais e tamanho do mercado - negociar através da iniciativa privada e do Estado uma participação importante na estruturação futura da economia mundial. A maior ou menor participação do Brasil e a forma de sua integração serão definidas nos próximos anos e vão depender, em grande medida, de uma decisão nossa. Isto é do tipo de projeto nacional que estruturarmos nesta fase de transição.

No caso específico do Brasil, a renitência do processo inflacionário, o desequilíbrio externo e o desemprego não podem ser atribuídos somente à crise econômica mundial, embora a mesma tenha agravado esses problemas. Do 11 pós-guerra até o presente o desequilíbrio externo, a inflação e o desemprego, no caso brasileiro, têm um caráter estrutural, na medida em que são uma constante no nosso processo de desenvolvimento. Tais problemas decorrem fundamentalmente da adoção de um processo de formação de capital que buscou reproduzir os padrões de consumo de economias industrializadas e com rendas per capita inúmeras vezes superiores à brasileira.

Entre o 11 pós-guerra e o início dos anos 60, embora as muitas distorções do processo de industrialização, que se deu em total desacordo com a nossa dotação relativa de fatores de produção, a economia brasileira experimentou uma das mais rápidas e profundas transformações de estrutura produtiva de que se tem notícia em países semi-industrializados de economia de mercado. De 1968 a 1973 o Brasil deu um exemplo extraordinário de economia semiindustrializada a realizar com sucesso a difícil transição de um desenvolvimento industrial, baseado no protecionismo concedido às atividades voltadas para o atendimento exclusivo do mercado interno, para uma fase de desenvolvimento com abertura crescente para o exterior, através da promoção de exportações não-tradicionais, através da progressiva liberalização do comércio exterior e da integração ao mercado internacional de capitais.

Entre 1974 e 1980, com a elevação dos preços do petróleo e no momento em que o mundo industrializado entra em crise e busca ajustar as suas economias através de políticas recessionistas, o governo brasileiro injeta grandes volumes de recursos na economia. A crise econômica - perfeitamente perceptível por uma série de 
circunstâncias - não se faz acompanhar por um decréscimo acentuado nas taxas de crescimento do produto, que situaram-se por volta de $7,5 \%$ ao ano entre 1974 e 1980, enquanto que nos países industrializados a queda no crescimento foi de $50 \%$. Isto é, de uma média de $5,5 \%$ no período $1968 / 1973$, passou para $2,6 \%$ no período 74/80. Na busca do objetivo correto de manter uma taxa de crescimento relativamente elevada, o País adota a estratégia errada de relizar um gasto público e privado, em investimento e consumo, muito superior a sua capacidade interna de produção, excitando a demanda por bens e serviços. O resultado foi o recrudescimento do processo inflacionário, menos exportações, mais importações e o agravamento do déficit em transações correntes. Simultaneamente, para financiar os seus gastos, o governo lança mais títulos no mercado, que pressionam a taxa de juros interna para cima e com isto é viabilizada a entrada de empréstimos externos, que passam a financiar o déficit em transações correntes. Esse processo de endividamente se deu através do aumento da participação do consumo (público e privado) no produto interno. Isto significa que o serviço da dívida competiu com o investimento na absorção da poupança, cuja taxa não foi aumentada (poupança interna), pois se chocaria com a lógica do modelo de crescimento baseado na produção de bens de consumo durável, cuja produção no período $1974 / 1980$ continuou crescendo a uma taxa superior à dos bens de capital e à dos bens de consumo não-durável, a exemplo do que ocorrera no período 1968/1973.

De 1980 ao presente a política econômica sofreu uma mudança de rumos, visando, fundamentalmente, corrigir o desequilíbrio externo. Tal política consiste basicamente em reduzir o dispêndio agregado da economia. Embora necessária tal correção, entendemos que a política econômica deveria ser mais seletiva com relação aos diferentes setores, favorecendo as atividades absorvedoras de mão-de-obra e as que, por seu dinamismo, sejam suficientemente capazes de instaurar um novo padrão de expansão da economia. Com relação ao primeiro objetivo, a política econômica deve reorientar os investimentos públicos e privados para: a) a produção de alimentos, que tem um peso maior nos orçamentos das familias de baixa renda. Para tanto seria necessário dotar estas pessoas de poder de compra, o que poderia ser feito, além de mecanismos diretos, como a adoção de uma política salarial de expansão do poder aquisitivo, e/ou através da concessão de subsídios ao consumo de alimentos. Esses subsídios não seriam inflacionários, desde que, em vez de saírem do orçamento monetário, fossem explici- 
tados no orçamento fiscal e com a clara definição dos grupos sociais financiadores. Acredito que não existiriam maiores condicionantes do lado da oferta, em termos de base física, desde que considerássemos o País como um todo e os incentivos governamentais de assistência técnica, infra-estrutura, crédito a taxas de mercado, seguro agrícola e preços compatíveis com os custos de produção; b) os segmentos industriais, cuja tecnologia é intensiva de mão-deobra e que são justamente as indústrias que produzem bens simples de consumo e que teriam a sua demanda dinamizada com uma meIhor distribuição de renda; c) as atividades de exportação, tendo em vista a necessidade de se gerar crescentes saldos comerciais para pagar-se a divida externa. E importante salientar que o setor exportador é altamente intensivo de mão-de-obra e com isto estar-seia atacando simultaneamente o desequilíbrio externo e o desemprego. Para termos uma idéia da alta intensidade de mão-de-obra do setor exportador, basta dizer que, enquanto cada 100 mil dólares de produção do setor industrial brasileiro absorvem, em média, 25 homens/ano em termo diretos e indiretos, as exportações de manufaturados absorvern em média 96 homens/ano em cada 100 mil dólares de produção; d) a produção de serviços públicos básicos de infra-estrutura social, que contribuiriam para alcançar, simultaneamente, dois objetivos: 1 -emprego de mão-deobra, pois são atividades intensivas em trabalho, principalmente o não-qualificado, embora requeiram pessoal mais qualificado quando entram em operação (hospitais, escolas, transporte urbano e outros) e 2 -redistribuição de renda via investimentos trabalho-intensivo e utilização por parte da classe operária desses serviços (os chamados salários indiretos como educação, saúde, transporte e outros).

Com relação ao segundo objetivo é necessário que o País elabore um plano de desenvolvimento do setor industrial, para um horizonte de longo prazo que contemple, além da questão energética. Pois é neste terreno que se dará a resolução da crise mundial, que é, sobretudo, uma crise do atual padrão industrial.

Neste sentido, muito já foi feito no País, que nos últimos anos realizou um dos maiores programas de investimento de que se tem notícia no mundo. Embora possamos questionar a prioridade de alguns desses investimentos, não podemos discutir a validade dos mesmos. A maior parte desses projetos é de substituição de importações de insumos básicos e que buscam preencher e viabilizar a atual estrutura industrial do País. De outro lado estão em 
andamento projetos ligados à energia nuclear e à busca de fontes energéticas alternativas, capacitando o País a ocupar uma posição de vanguarda no novo ciclo econômico mundial que a atual crise está gestando. 